Asian-Australasian Journal of

Food Safety and Security

ISSN 2523-1073 (Print) 2523-2983 (Online)

www.ebupress.com/journal/aajfss

\title{
Article \\ Isolation and characterization of antibiotic resistant bacteria from pre and post- microwave oven treated burger sold in Mymensingh
}

\author{
Mohammad Arif Haider ${ }^{1}$, Samina Ievy ${ }^{1}$, Md. Abdus Sobur ${ }^{1}$, Md. Muket Mahmud ${ }^{1}$, Muhammad Tofazzal \\ Hossain $^{1}$, A. M. Md. Taufiqur Rahman ${ }^{2}$, K.H.M. Nazmul Hussain Nazir ${ }^{1}$ and Md. Tanvir Rahman ${ }^{1}$ * \\ ${ }^{1}$ Department of Microbiology and Hygiene, Faculty of Veterinary Science, Bangladesh Agricultural University, \\ Mymensingh-2202, Bangladesh \\ ${ }^{2} 100$ Bedded Naogaon District Hospital, Naogaon, Bangladesh
}

*Corresponding author: Professor Dr. Md. Tanvir Rahman, Department of Microbiology and Hygiene, Faculty of Veterinary Science, Bangladesh Agricultural University, Mymensingh-2202, Bangladesh. E-mail: tanvirahman@bau.edu.bd

Received: 28 March 2018/Accepted: 10 May 2018/ Published: 31 May 2018

\begin{abstract}
Burger is one of the common popular fast food. The present study was carried out to isolate and characterize bacteria from burger sold in Mymensingh that could be potential threat to human health. A total of 20 burger samples (10 belonged to pre-microwave oven treated group and 10 belonged to post-microwave treated group) were collected randomly from different bakeries and fast food shops that sell burgers in Mymensingh. Isolation and identification of bacteria were carried out based on morphology, staining, cultural and biochemical tests. All the samples were found contaminated with bacteria. Total viable count (TVC), total staphylococcal count (TSC) and total coliform count (TCC) of pre-microwave oven burger samples were $7.22 \pm 0.20 \log \mathrm{CFU} / \mathrm{g}, 6.93 \pm 0.30 \mathrm{log} \mathrm{CFU} / \mathrm{g}$ and $3.28 \pm 0.64 \mathrm{log} \mathrm{CFU} / \mathrm{g}$, respectively. Similarly in postmicrowave oven treated burger the TVC, TSC and TCC were $3.09 \pm 0.42 \log$ CFU/g, $2.84 \pm 0.56 \log$ CFU/g and $1.60 \pm 0.42 \log \mathrm{CFU} / \mathrm{g}$, respectively. Microwave heat treatment for 60 seconds markedly reduced the TVC, TSC, TCC in the burger compared to pre microwave treated group. Many of the both the pre and post-microwave oven treated burgers were found positive for Staphylococcus spp. and E. coli. The isolates of Staphylococcus were found coagulase negative and resistant to Tetracycline while sensitive to Azithromycin, Gentamycin, Kanamycin and Streptomycin. On the other hand, the isolates of E. coli were found resistant to Azithromycin and Streptomycin while sensitive to Gentamycin, Kanamycin and Tetracycline. Data of this study suggested that burgers sold in the fast food restaurant were contaminated with antibiotic resistant Staphylococcus and E. coli that might be considered as human health hazard.
\end{abstract}

Keywords: burger; microwave oven treatment; Staphylococcus; E. coli; antibiotic resistant

\section{Introduction}

Burger is found almost in every fast food shops. It is made of combination of bread, cutlet, salads, sauce etc. It is frequently eaten as a snack during lunch or afternoon, birthday party or marriage ceremony and as tiffin for the children as an alternate of regular food items and so on. Burger is a ready to eat meat products with high demand due to their high biological value, reasonable price, agreeable taste and easy during serving (SolimanSalawa R, 1999).

Burger might be one of the worst offenders when it comes into food poisoning. Burger may harbor a number of pathogenic bacteria such as, Campylobacter spp., E. coli, Listeria monocytogenes, Salmonella spp., Staphylococcus spp. etc (Guillier et al., 2013; Shawish and Al-Humam, 2016). These pathogens spread by burger not only affects large groups of people, but also sometimes result in serious disability and even death. The transmission of human diseases through food is a global problem, particularly in developing countries 
where gastrointestinal diseases are one of the most important causes of morbidity and mortality. However, food habits adopted by populations may mitigate or increase the hazards. These hazards can be minimized to a great extent simply by monitoring the microbiological quality of food and creating awareness among the people about the fundamental principles of sanitation and hygienic quality of foods.

Bare-handed handling of foods and use of unsafe water for dish washing and hand washing by food handlers, keeping food for long time under lighting in display glass boxes with elevated temperatures and storage of breads and uncooked and half cooked meat items side by side in the refrigerator are known to be the possible sources and causes of microbiological contamination of the fast food items (Faruk and Akhter, 2011). To check whether burgers sold in the marked are safe for the consumer, microbiological assessment of burger is essential from time to time from public health points of view. More than decades ago Rahman et al. (1998) performed bacteriological monitoring of bakery food and environment in Mymensingh area. No study has yet been performed on the assessment of bacterial load and their characteristics found in burger sold at bakery and fast food restaurant in Mymensingh recently. Present study was designed to determine the bacterial load of burger sold in Mymensingh. In addition, samples were also analyzed to detection the occurrence of antibiotic resistant bacteria in the burgers that may be a threat to consumers health.

\section{Materials and Methods}

The present study was conducted during the period of January, 2017 to June 2017, in the Department of Microbiology and Hygiene, Bangladesh Agricultural University (BAU), Mymensingh. Burger samples ( $\mathrm{n}=20$ ) were collected aseptically on random basis from different bakery and fast food shops of BAU campus and Mymensingh city and immediately transported to lab for analysis. All that samples were divided into two categories: pre-microwave oven sample (fresh sample from retail outlets, $n=10$ ) and post-microwave oven sample (treated for 1 minute in microwave oven, $\mathrm{n}=10$ ). Isolation and identification of bacterial species from then burger were carried out based on morphology, Gram's staining, cultural characteristics on selective media like Mannitol Salt (MS) agar, Eosin Methylene Blue (EMB) agar, Salmonella Shigella (SS) agar and biochemical test (sugar fermentation test, coagulase test, catalase test as described by Cheesbrough (1985).

In addition, Total Viable Count (TVC), Total Staphylococci Count (TSC) and Total Coliform Count (TCC) of the samples were determined to evaluate the total load using Plate Count Agar, Mannitol Salt agar and EMB agar respectively using the guideline of ICMSF (1998). In brief, initially a 10-fold serially dilution was made from each sample. From each dilution, $10 \mu \mathrm{l}$ were poured on each part for 3 times and incubated at $37^{\circ} \mathrm{C}$ for development of CFU for $24 \mathrm{hrs}$. After incubation, plates exhibiting 30-300 colonies were counted. The average number of colonies in particular dilution was multiplied by the dilution to obtain the total viable count. The total viable count was calculated according to the method of ISO (1995). The results of the total bacterial countexpressed as mean log colony forming unit (CFU) per gram.

The antibiogram of the isolated bacteria were determined as described by Mamun et al., (2017) using disk diffusion test on Mueller Hinton media (HiMedia). Antibiotic used in this study were Azithromycin (15 $\mu \mathrm{g} / \mathrm{disc})$, Gentamicin (10 $\mu \mathrm{g} / \mathrm{disc})$, Kanamycin $(30 \mu \mathrm{g} / \mathrm{disc})$, Tetracycline $(30 \mu \mathrm{g} / \mathrm{disc})$, Streptomycin (10 $\mu \mathrm{g} / \mathrm{disc})$. Antimicrobial testing results were recorded as sensitive, intermediately sensitive or resistant and the zone of growth inhibition was compared with the zone size interpretative tables provided by Clinical and laboratory Standards Institute (CLSI 2013).

\section{Results}

\subsection{Total bacterial load}

The TVC of pre-microwave oven treated burger samples ranged between 6.63 to $8.03 \mathrm{log} \mathrm{CFU} / \mathrm{g}$. On the other hand, the TVC of post microwave oven treated burger samples ranged from 0 to $4.71 \log$ CFU/g (Figure 1). The mean TVC of pre-microwave oven treated burger samples were 7.22 $\pm 0.20 \log$ CFU/g and post-microwave oven treated burger samples were $3.09 \pm 0.42 \log$ CFU/g (Table 1). 


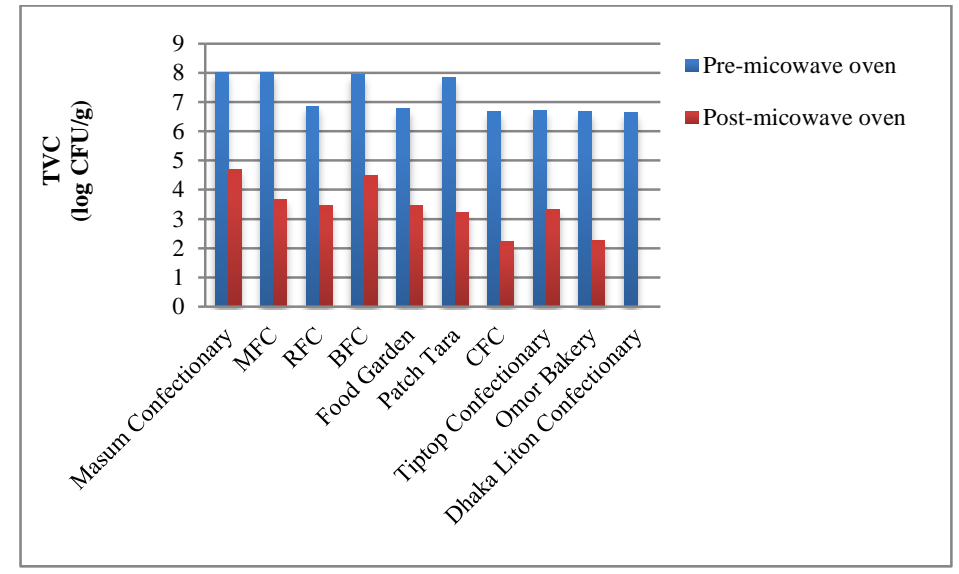

Figure 1. Total viable count (TVC) of pre-microwave oven treated and post-microwave oven treated burger samples. The results of TVC are expressed as log CFU/gm.

Table 1. Comparison between the mean value of TVC, TSC and TCC of pre-microwave oven treated and post-microwave oven treated burger samples.

\begin{tabular}{llll}
\hline Parameters & TVC $(\log$ CFU/g) & TSC $(\log$ CFU/g) & TCC (log CFU/g) \\
\hline Pre-microwave oven & $7.22 \pm 0.20$ & $6.93 \pm 0.30$ & $3.28 \pm 0.64$ \\
Post-microwave oven & $3.09 \pm 0.42$ & $2.84 \pm 0.56$ & $1.60 \pm 0.42$ \\
\hline
\end{tabular}

Microwave treatment markedly reduced the TVC of burger (Figure 1). The highest TVC was observed in premicrowave treated burger samples collected from Masum confectionary and the lowest TVC was observed in pre-microwave treated burger samples collected from Dhaka Liton Confectionary (Figure 1). Similarly highest TVC was observed in post-microwave treated burger samples collected from Masum confectionary (Figure 1) and the lowest TVC was observed in post-microwave treated burger samples collected from Dhaka Liton Confectionary.

The TSC of pre-microwave oven treated burger samples ranged between 5.45 to 7.99 log CFU/g while the TSC of post-microwave oven burger samples ranged from 0 to $4.58 \log \mathrm{CFU} / \mathrm{g}$ (Figure 2).

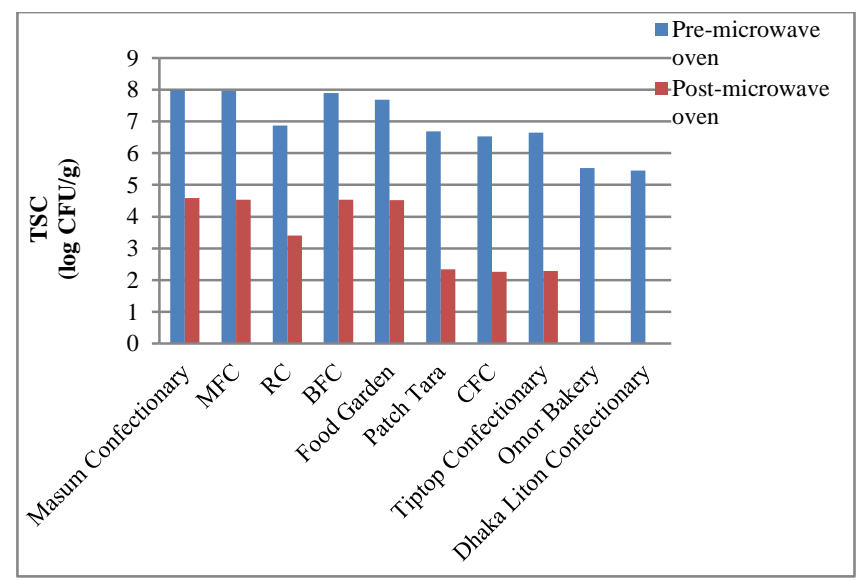

Figure 2. Total Staphylococcal count (TSC) of pre-microwave oven treated and post microwave oven treated burger samples. The results of TSC are expressed as log CFU/gm.

The mean TSC of pre-microwave oven burger samples were $6.93 \pm 0.30 \mathrm{log}$ CFU/g and post microwave oven treated burger samples were $2.84 \pm 0.56 \log \mathrm{CFU} / \mathrm{g}$ (Table 1 ). The highest TSC was observed in pre-microwave burger samples collected from Masum confectionary (Figure 2) and the lowest TSC was observed in premicrowave burger samples collected from Dhaka Liton Confectionary. On the other hands, the highest TSC was observed in post-microwave burger samples collected from Masum confectionary and the lowest TSC was 
observed in post-microwave treated burger samples collected from Omor Bakery and Dhaka Liton Confectionary.

The TCC of pre-microwave oven treated burger samples ranged between 0 to $5.68 \mathrm{log} \mathrm{CFU} / \mathrm{g}$. On the other hand, the TCC of post-microwave oven treated burger samples ranged from 0 to $3.48 \mathrm{log}$ CFU/g) (Figure 3).

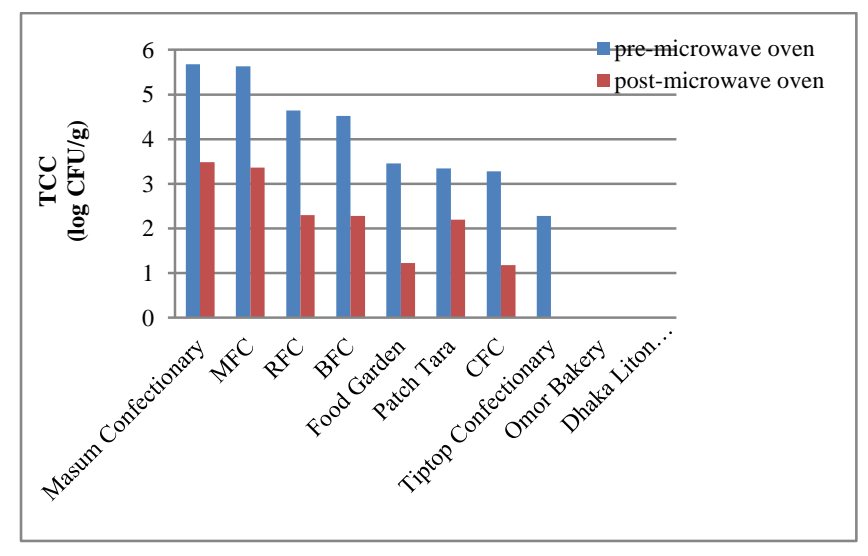

Figure 3. Total Coliform count (TCC) of pre-microwave oven treated and post microwave oven. The results of TSC are expressed as log CFU/gm.

The highest TCC was observed in pre-microwave treated burger samples collected from Masum confectionary (Figure 3) and the lowest TCC was observed in pre-microwave treated burger samples collected from Omor Bakery and Dhaka Liton Confectionary. On the other hands, the highest TCC was observed in post-microwave treated burger samples collected from Masum confectionary and the lowest TCC was observed in postmicrowave burger samples collected from Tiptop Confectionary, Omor Bakery and Dhaka Liton Confectionary.

\subsection{Isolation of bacteria}

Several isolates of Staphylococcus spp. and E. coli were isolated and identified from the burger samples. The occurrence of Staphylococcus spp. and E. coli in burgers collected from various bakeries is presented in Table 2 . Isolated Staphylococcus spp. were subjected top coagulase test and all were found coagulase negative.

Table 2. Distribution patter of Staphylococcus spp. and E. coli in burgers collected from various bakeries in Mymensingh.

\begin{tabular}{llllll}
\hline Sample & Name of the bakery/fast & \multicolumn{2}{c}{ Pre-microwave oven } & \multicolumn{2}{c}{ Post-microwave oven } \\
\cline { 2 - 6 } No. & food shop & Staphylococcus spp. & E. coli & Staphylococcus spp. & E. coli \\
\hline 1 & Masum Confectionary & + & + & + & + \\
2 & MFC & + & + & + & + \\
3 & RFC & + & + & + & + \\
4 & BFC & + & + & + & + \\
5 & Food Garden & + & + & + & + \\
6 & Patch Tara & + & + & + & + \\
7 & CFC & + & + & + & - \\
8 & Tiptop Confectionary & + & + & + & - \\
9 & Omor Bakery & + & - & - & - \\
10 & Dhaka Liton Confectionary & + & - & - & + \\
\hline
\end{tabular}

Post-microwave oven treated burger from Omor Bakery and Dhaka Liton Confectionary were found negative for Staphylococcus and E. coli (Table 2). Post-microwave oven treated burger from Tiptop Confectionary were also found negative for E. coli. Pre-microwave oven treated burger from Omor Bakery and Dhaka Liton Confectionary were found negative for E. coli. All other samples were found positive for Staphylococcus and E. coli.

\subsection{Antibiotic sensitivity test}

Isolated Staphylococcus spp. and E. coli were subjected to antibiotic sensitivity assay. From the antibiogram it was evident that the isolated coagulase negative Staphylococcus (CNS) were found resistant to Tetracycline 
while sensitive to Azithromycin, Gentamycin, Kanamycin and Streptomycin. On the other hand, the isolated $E$. coli were found resistant to Azithromycin and Streptomycin while sensitive to Gentamycin, Kanamycin and Tetracycline.

\section{Discussion}

Food is one of the basic needs of the human body. Fast food plays a very important role in urban human life. Foods specially fast food may cause many types of diseases in the human body as fast food is made in a very short period of time in which all the hygienic procedure may not be maintained. The unhygienic and unsafe treatment of food is seriously impacting public health by causing numerous chronic and non-chronic diseases (Ali, 2013).

In this study the bacteriological quality of the selected burger samples were evaluated. The mean TVC, TSC and TCC of pre-microwave oven burger samples were $7.22 \pm 0.20 \log \mathrm{CFU} / \mathrm{g}, 6.93 \pm 0.30 \mathrm{log} \mathrm{CFU} / \mathrm{g}$ and $3.28 \pm 0.64 \log$ CFU/g, respectively. Similarly in post-microwave oven burger samples the TVC, TSC and TCC were $3.09 \pm 0.42 \log \mathrm{CFU} / \mathrm{g}, 2.84 \pm 0.56 \mathrm{log} \mathrm{CFU} / \mathrm{g}$ and $1.60 \pm 0.42 \mathrm{log}$ CFU/g, respectively. These findings are comparatively higher compared to those reported by Faruk and Akhter (2011). These authors analyzed burger samples found in Dhaka city having lower TVC, TSC and TCC, suggesting that hygienic conditions in the bakery/fast food is better in Dhaka compared to Mymensingh.

In this study bacterial content (TVC, TCC and TSC) of the pre-microwave oven treated burger was found higher compared to post-microwave oven treated (I minute exposure) burger (Table 1). However, this was not unexpected. Microwave is known to be detrimental for bacteria due to heat generation. Aziz and Youssef (2002) investigated the effect of microwave treatments of different beef products (burger, Pizza, Hot dog) on the survival and growth of bacteria. These authors showed that when heated in microwave oven bacterial counts following 20 to 30 second exposures.

In this study Staphylococcus spp. and E. coli were found to be present in both pre-microwave oven treated and post-microwave oven treated burger samples. Food borne pathogens are of high concern for public health and food safety. Staphylococcal food poisoning is one of the most economically devastating types of food poisoning globally. E. coli is also an important food borne pathogen. The identity of Staphylococcus spp. and E. coli were confirmed by biochemical tests. Although we did not do any further investigation on the pathogenicity of isolated Staphylococcus spp. and E. coli, but it may be speculated that some of them could be pathogenic and are of great public health concern. In addition, presence of $E$. coli may be considered as an indication of fecal contamination. El Shrek and Ali (2012) in a study earlier reported the occurrence of Staphylococcus and E. coli in chicken burgers sold in Tripoli City.

Isolates of Staphylococcus spp. found in the burger were screened for pathogenicity by coagulase test. All the isolates were found coagulase negative. Mucosal colonisation by coagulase negative Staphylococcus (CNS) is well established (Costa et al., 2004). The coagulase negative Staphylococci is a normal flora of the human skin, respiratory tract, urethra, external ear and mouth. CNS can also cause disease. These organisms have relatively low virulence but are increasingly recognized as agents of clinically significant infection of the bloodstream and other sites (Becker et al., 2014). Their presences in the burger samples are known to be probably due the unwholesome practices of the food handlers (Nwamaka et al., 2010).

Antibiotic resistant bacteria are global health problem andmany are known to spread through food to human. Staphylococcus spp. (CNS) isolated in this study were found resistant to Tetracycline while sensitive to Azithromycin, Gentamycin, Kanamycin and Streptomycin. In this study several E. coli were isolated from the burgers and found resistant to Azithromycin and Streptomycin while sensitive to Gentamycin, Kanamycin and Tetracycline. Sultana (2016), identified multidrug resistant bacteria from Burger sold at Dhaka city. In addition we also detected E. coli in burger resistant to Azithromycin. Previously Rahman et al. (1999) detected antibiotic resistant S. aureus from bakery food and environment in Mymensingh. Occurrence of antibiotic resistant bacteria in burger sold in the fast food restaurant and bakery might be considered as threat to its consumers.

\section{Conclusions}

Present study indicates that both pre and post-microwave oven treated burger sold in local fast food shop and bakery in Mymensingh is contaminated with bacteria including antibiotic resistant CNS and E. coli that might be considered as public health hazard. Maintaining good hygienic conditions during the processing and preparation of burger need to be ensured for production of burger free of microbial health hazard. 


\section{Acknowledgements}

This study was performed in partial fulfillment of the requirements of a M.S. thesis for Mohammad Arif Haider from the Department of Microbiology and Hygiene, Bangladesh Agricultural University, Mymensingh, Bangladesh. We are thankful to all the staff of the Department of Microbiology and Hygiene, Bangladesh Agricultural University, Mymensingh for their support.

\section{Conflict of interest}

None to declare.

\section{References}

Ali ANMA, 2013. Food safety and public health issues in Bangladesh: a regulatory. European Food and Feed Law Review. 8: 31-40. C. Food Technol., 13: 437-444.

Aziz NH and SR Youssef, 2002. Effect of gamma-ray and microwave treated on the shelf life of beef products stored at 50C. Food Technol., 13: 437-444.

Becker K, C HeilmannCand G Peters, 2014. Coagulase-Negative Staphylococci. Microbiol. Rev., 27: 870-926.

El ShrekYM and MR Ali, 2012. Microbiological study of spiced chicken burgers in Tripoli City, Libya]. East Mediterr Health J., 18: 653-662.

Cheesebrough M, 1985. Medical Laboratory manual for tropical countries.1st edition Microbiology. English Language Book Society, London. pp. 400-480.

CLSI, 2013. Performance Standards for Antimicrobial Disk Susceptibility Tests; Approved Standard-Eleventh Edition. CLSI document M02-A11. Wayne, PA; 2013; Clinical and Laboratory Standards Institute

Costa SF, MH Miceli and EJ Anaissie, 2004. Mucosa or skin as source of coagulase-negative staphylococcal bacteraemia? Lancet Infect. Dis., 4: 278-286.

Faruk MO and MZ Akhter, 2011. Presence of coliforms and fecal coliforms in fast food items Of local restaurants and fast food outlets of Dhaka city, Department of Microbiology, University of Dhaka. Bangladesh J. Microbiology, 28: 49-51.

Guillier L, C Danan, H Bergis H, ML Delignette-Muller, S Granier, S Rudelle, A Beaufort and A Brisabois, 2013. Use of quantitative microbial risk assessment when investigating foodborne illness outbreaks: the example of a monophasic Salmonella Typhimurium 4, 5, 12: i:- outbreak implicating beef burgers. Int. J. Food Microbiol.,116: 471-478.

ICMSF, 1998. Microorganisms in Foods. Microbial ecology of food commodities. 6: 615-616.

ISO, 1995. Recommendation of meeting of the subcommittee, International Organization for standardization on meat and meat products. Iso/tc $36 \mathrm{sc}-6.10-18$.

MamunMM, J Hassan, KHMNA Nazir, MA Islam, K Zesmin, MB Rahman and MT Rahman, 2017. Prevalence and molecular detection of quinolone-resistant E. coli in rectal swab of apparently healthy cattle in Bangladesh. Int. J. Trop. Dis. \& Health. 24: 1-7.

Nwamaka NT, A Chike and A Obiajulu, 2010. Role of bacteria isolates in the spoilage of Fermented African oil bean seed "ugba". Pakistan. J. of Biological Science, 13: 497-503.

Rahman MT, MM Rahman and MA Islam, 1998. Bacteriological monitoring of bakery foods and its environment. Bangladesh Vet. J., 32: 27-32.

Rahman M.T, MM Rahmanand MA Islam, 1999. Distribution and prevalence of chloramphenicol resistant Staphylococcus aureus in bakery food and environment. The Bangladesh Veterinarian, 16: 12-14.

Shawish RR and NA Al-Humam, 2016. Contamination of beef products with staphylococcal classical enterotoxins in Egypt and Saudi Arabia. GMS Hyg. Infect. Control, 11: 1-6.

Soliman-Salawa R, 1999. Risk of street food vending on public health. M.V.Sc. Thesis, Fac. Vet. Cairo University. 